\title{
Recorregut de recerca geològica i mineralògica per la comarca del Pallars Jussà: des de Senterada, a la Pobleta de Bellveí, al Castell i a Sallente
}

Josep Maria Mata-Perelló

Joaquim Sanz Balagué

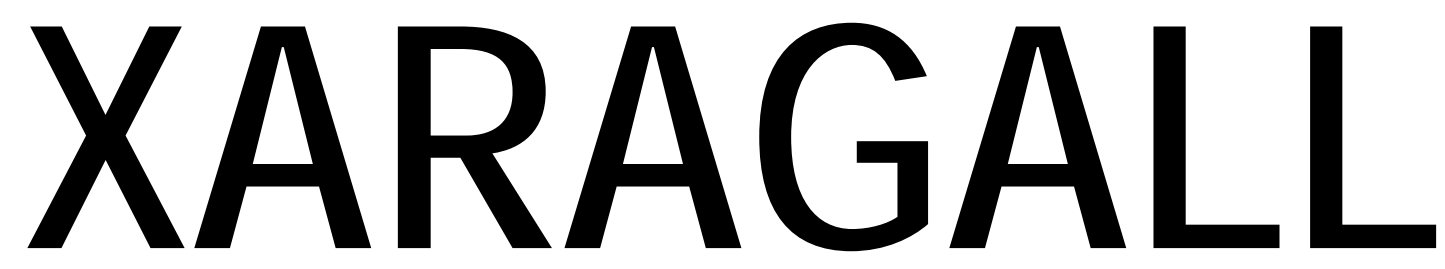

REVISTA DE CIÈNCIES DE LA CATALUNYA CENTRAL

\section{n. 3}

MARÇ 2015 


\title{
RECORREGUT DE RECERCA GEOLÒGICA I MINERALÒGICA PER LA COMARCA DEL PALLARS JUSSÀ: DES DE SENTERADA, A LA POBLETA DE BELLVEÍ, AL CASTELL I A SALLENTE
}

\author{
Josep Maria Mata-Perelló \\ Museu de geologia Valentí Masachs, Escola Politècnica Superior d'Enginyeria de Manresa \\ (EPSEM), Universitat Politècnica de Catalunya · BarcelonaTech (UPC), 08272 Manresa, Spain
}

\section{Joaquim Sanz Balagué}

Departament d'Enginyeria Minera i Recursos Naturals (EMRN), Escola Politècnica Superior d'Enginyeria de Manresa (EPSEM), Universitat Politècnica de Catalunya - BarcelonaTech (UPC), 08272 Manresa, Spain

Paraules clau: Sistema Pirinenc, Meterials mesozoics, Materials paleozoics, Patrimoni miner

\section{Resum}

Itinerari realitzat el 8 d'agost de 2014. En aquesta ocasió, la totalitat del recorregut de l'itinerari es desenvoluparà per una sola unitat geològica: concretament pel Sistema Pirinenc, i més exactament per la zona de contacte entre la Unitat de Bóixols i la Unitat de les Nogueres, situada al nord de l'anterior. D'aquesta manera, el recorregut s'iniciarà a la població de Senterada (situada a la Unitat de les Nogueres, però molt prop del contacte acabat d'esmentar).

Així, a partir d'equí l'itinerari transitarà per la dita Unitat de les Nogueres (o Unitat del Mantell de les Nogueres). Així, s'aniran trobant afloraments dels materials mesozoics del Cretàcic i del Triàsic, al principi del recorregut. Més endavant es trobaran afloraments paleozoics del Silurià, Devonià, Carbonífer i Permotries.

Per altra banda, aquest itinerari es desenvoluparà dintre de la comarca del Pallars Jussà (per la qual es transitarà entre la Senterada i la fi del recorregut, per les immediacions de la població de Cabdella).

Així, tot el recorregut de l'itinerari s'efectuarà per la Vall Fosca, una subcomarca del Pallars Jussà. Aquesta subcomarca es troba situada íntegrament dintre de la conca fluvial del Noguera de Flamisell, afluent del Noguera Pallaresa a la Pobla de Segur. 


\section{Objectius fonamentals}

Es centraran en els aspectes geològics, geomorfològics i mineralògics que apuntarem a continuació:

1. Observació i descripció a distancia dels materials mesozoics que cenozoics que formen part de la Unitat de Bóixols; que trobarem fonamentalment per les immediacions de Senterada, per la zona de contacte entre aquesta unitat i la Zona de les Nogueres, situada una mica més cap al Nord. Els materials mesozoics que trobarem pertanyen fonamentalment al Cretàcic (amb nivells carbonatats de calcaries i calcolutites) i al Triàsic (amb nivells de gresos, calcaries, guixos, argiles i ofites, segons els llocs).

2. Observació dels materials que constitueixen la Unitat de les Nogueres, que anirem trobant entre Senterada i la Torre de Cabdella. Aquests materials pertanyen al mesozoic (exclusivament al Triàsic Superior) i al paleozoic, repartint-se entre el Permotries, el Carbonífer, el Devonià i el Silurià). Així, trobarem afloraments del Keuper (amb trams de guixos, argiles i ofites), del Permotries (amb gresos rogencs), del Carbonífer (amb trams d'esquistos negres, fonamentalment), del Devonià (amb trams de calcàries ) i del silurià (amb pissarres negres, molt grafitoses i piritoses)

3. Observació de les relacions existents entre les diferents làmines d'encavalcament, de les dues unitats anteriors. Precisament, com ja hem avançat, una part del recorregut de l'itinerari s'efectuarà per les immediacions de la zona de contacte entre les dues unitats geològiques acabades d'esmentar.

4. Observació de les diferents mineralitzacions que anirem trobant al llarg del recorregut, com les següents, d'acord amb el sentit de la marxa:

4A) de les mineralitzacions evaporítiques de GUIX, situades prop del poble de Senterada, entre els materials triàsics del Keuper.

4B) de les mineralitzacions uraniníferes associades a "red-beds", del Castell, i situades entre els materials del Permotries.

4C) de les mineralitzacions filonianes de $P b-Z n$, de Mont-rós, encaixades entre els nivells paleozoics del Devonià.

4D) de les mineralitzacions filonianes de $\mathrm{Cu}$, encaixades entre els materials del Devonià, les quals es troben a la Torre de Cabdella.

5. Observació al llarg del recorregut de l'itinerari de les antigues explotacions, relacionades amb les mineralitzacions esmentades a l'apartat anterior. Al mateix temps, també observarem altres explotacions dels materials geològics, que es vagin trobant al llarg del recorregut de l'itinerari.

6. Observació de l’impacte produït sobre el Medi Natural, tant de la mineria com a conseqüència de les obres efectuades per la zona.

7. Observació dels indrets relacionats amb el patrimoni geològic, que es vagi trobant al llarg del recorregut. Dintre d'aquest apartat, cal fer esment de les mineralitzacions cupro uraniníferes associades a red - beds, que trobarem al Castell

8. Observació dels indrets relacionats amb el patrimoni miner, que es vagi trobant al llarg del recorregut. Aquí cal fes esment de les instal-lacions mineres del Castell, entre altres indrets del recorregut. 


\section{Antecedents}

Pel que fa al recorregut del present itinerari, existeixen uns antecedents nostres, relatius a altres itineraris geològic i miners proper al que ara presentem. Aquests antecedents, són: mata Perelló (1995, 1996a, 1996b, 1998a, 1998b, 2000, 2002, 2003, 2005, 2009, 2010, 2012 i 2013). També cal al fer esment del treball de Mata Perelló i Montané (2003).

Pel que fa a la descripció de les mineralitzacions, cal parlar d'un altre treball, també nostre; en concret de Mata Perelló (1991). Aquest treball es relatiu a les mineralitzacions catalanes en general, amb un capítol dedicat a la Noguera. També cal fer esment de Mata Perelló i Sanz (1993), dedicat al reconeixement dels minerals.

I pel que fa a l'estructura geològica de la zona per la qual discorre l'itinerari, farem esment de dos treballs, molt interessants, de caràcter generalista. En concret, ens estem referint als següents: Guimerà et altri (1982). i també a Riba et altri (1976). Tots dos treballs es refereixen a la geologia dels Països Catalans, i conseqüentment de Catalunya. Per d'altra banda, també cal fer esment del treball de Rosell (1970); així com de l'IGME (1994).

Tots aquests treballs referenciats, i d'altres, figuren esmentats per ordre alfabètic a l'apartat dedicat a la BIBLIOGRAFIA.

\section{Recorregut de l'itinerari}

El recorregut de l'itinerari discorrerà per una comarca de la Regió de Tremp - la Seu d'Urgell; concretament per la del Pallars Jussà. Així, el recorregut s'iniciarà a la població de Senterada, situada a la Vall del Flamisell, que ara remuntarem, dintre del Mantell de la Zona de les Nogueres, però molt prop del Mantell de Bóixols. Tot i així, aquesta darrera unitat pirinenca, no $s^{\prime}$ arribarà a tallar en cap moment del recorregut d'aquest itinerari.

Després, l'itinerari continuarà cap a la Pobleta de Bellvei, per la carretera local de Cabdella, per tal d'arribar fins a la Plana de Mont-rós. Des d'aquí s'anirà cap Castell, per tal de fer una aturada a les antigues mines d'urani. En aquest tram del recorregut, s'aniran fent diverses aturades. Així, s'anirà seguint sempre la carretera local $L-503$, que va remuntant la Vall Fosca i el riu Flamisell.

Després de retornar a la Plana de Mont-rós caldrà fer una fillola, primer cap a Mont-rós i després cap a la Torre de Cabdella, per on es farien dues noves aturades, si es donés aquest cas. Tot aquest recorregut es farà sempre dintre del Mantell de la Zona de les Nogueres.

El recorregut finalitzarà en aquesta població, en una situació més o menys propera a la Zona Axial Pirinenca. 


\section{Advertiments previs}

Com en altres recorreguts de RECERCA GEOLÒGICA I MINERALÒGICA... si es disposa del temps suficient, poden efectuar-se passant per totes les parades i filloles. En cas contrari, recomanem prescindir de les anomenades PARADES - CONDICIONALS.

També cal tenir en conte que una part del recorregut de l'itinerari, es realitzarà per camins de terra, per la qual cosa caldrà prendre les degudes precaucions, especialment en els camins d'accés a les diferents mines.

Cal tenir, com sempre, una cura molt especial de respecte a la natura, al llarg de tot el recorregut de l'itinerari, i també fora d'ell.

\section{Descripció de l'itinerari}

En aquest recorregut hem situat, com ja és habitual en tots els itineraris, una sèrie d'ESTACIONS o de PARADES, que anirem veient a continuació. En cada cas, els hi donarem una denominació que podrà correspondre a algun paratge proper. També indicarem el terme municipal i la comarca on es troba. Per d'altra banda, en cada una de les parades, indicarem entre parèntesi el número del "Mapa Topográfico", a escala 1:50.000, on es troba situada la parada considerada. En aquesta ocasió serà algun dels següents: 213 (o de Pont de Suert; 214 (o de Sort) i 252 (Tremp). Així doncs, la relació ordenada de les parades que composen aquest recorregut, és la següent:

\subsection{Parada 1. GUIXERA DE SENTERADA, (terme municipal de Senterada, comarca del Pallars Jussà). (Full 252).}

El recorregut d'aquest itinerari, caldrà fer-lo a tocar de la població de Senterada. Aquesta es troba a la cruilla de les carreteres $N-260$ i $L-503$. També es troba a l'aiguabarreig del riu Bòssia amb la Noguera de Flamisell. Nosaltres, situats a Senterada, agafarem la carretera local $L-503$, remuntant la Noguera de Flamisell. Aproximadament, a $1 \mathrm{Km}$ de I'inici, farem la primera aturada d'aquest itinerari, poc després de la sortida de Senterada.

En aquest breu recorregut, haurem circulat per entre afloraments dels materials triàsics del Keuper, els quals formen part del Mantell de la Zona de les Nogueres, on ara ens trobem situats, des de poc després de la parada anterior.

En aquest indret hi ha un aflorament dels materials triàsics del Keuper. Aquests estan formats per trams de guixos i d'argiles. Aquí afloren els primers, els quals han estat explotats en una antiga guixera. (fotografía 1). 


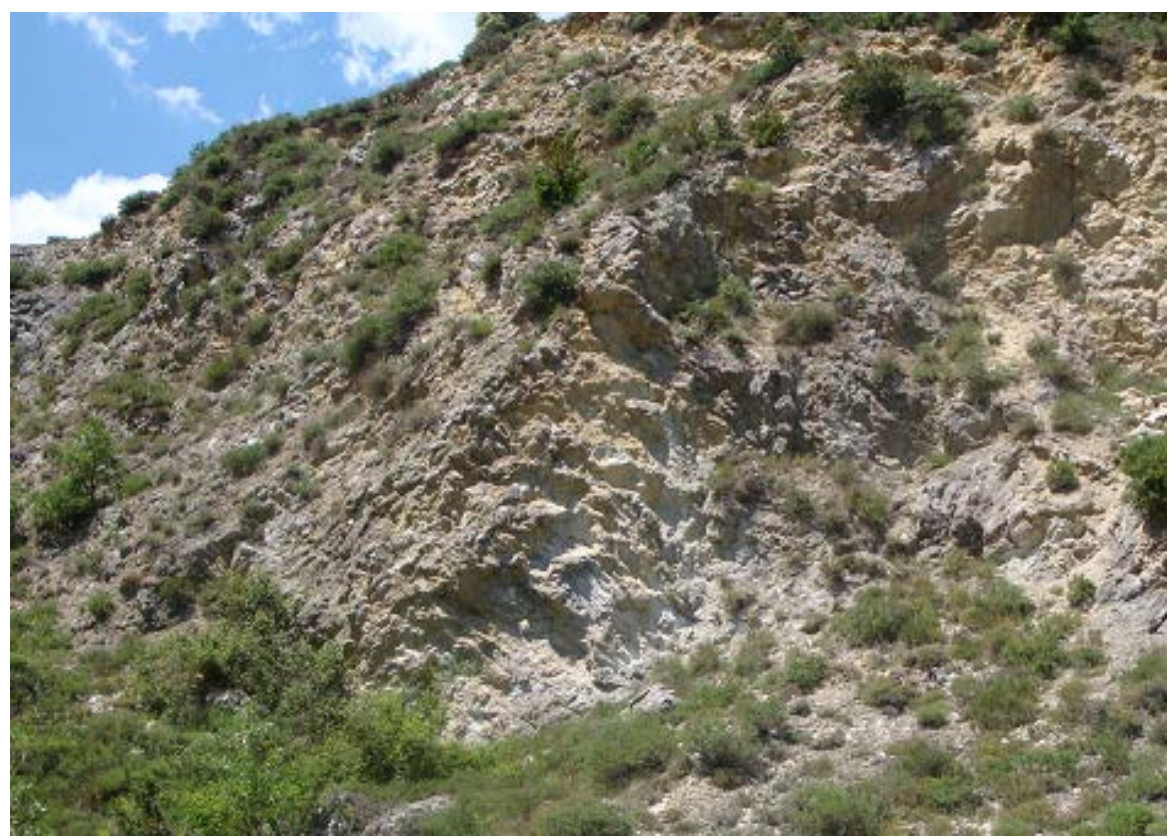

Fotografia 1. Antiga guixera de Senterada. Aflorament dels guixos triàsics del Keuper. Març 2006

Per altra banda, en aquest indret es troben les restes d'un antic Forn de Guix. En ell $s^{\prime}$ utilitzaven els guixos que afloren en aquest indret. Pel que fa al forn, cal dir que es troba molt mal conservat. (fotografia 2).

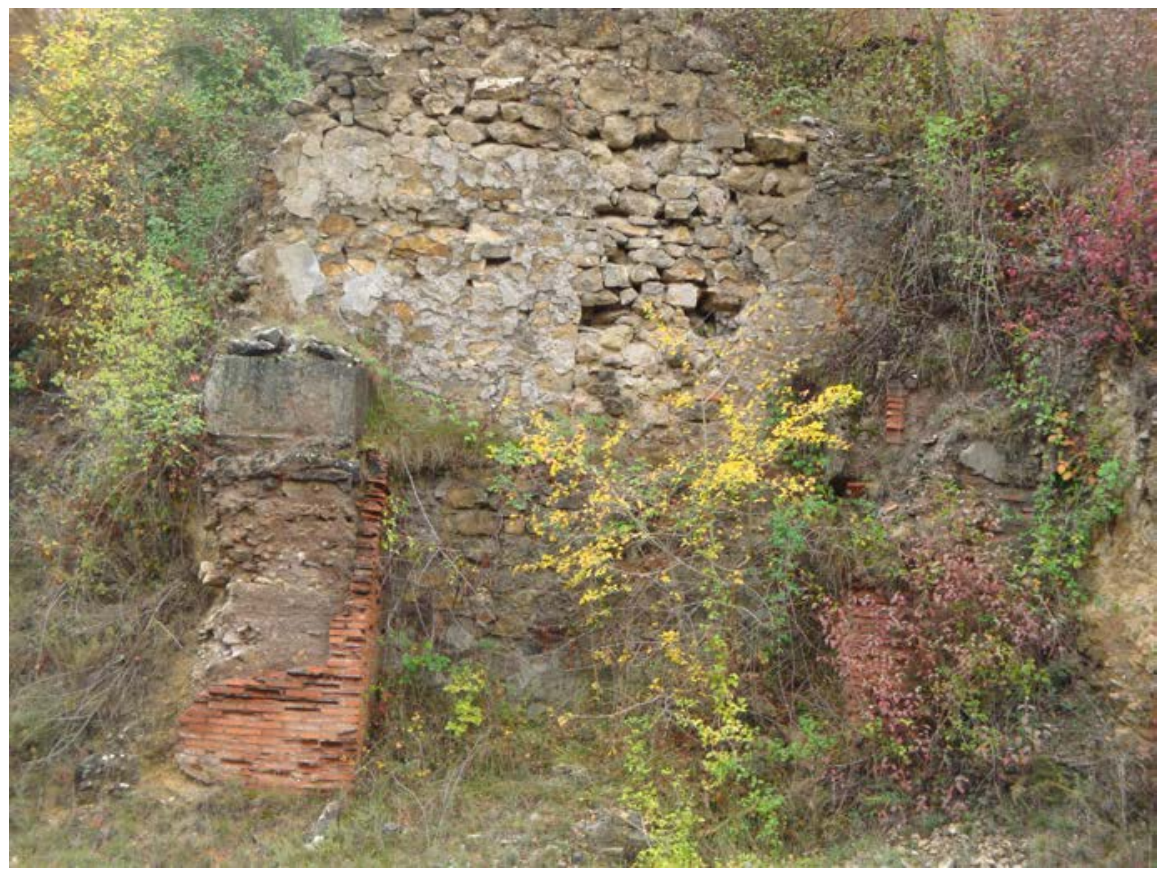

Fotografía 2. Restes del Forn de Guix de Senterada. S'utilitzaven els guixos del Keuper explotats a la guixera propera. guixera de Senterada. Aflorament dels guixos triàsics del Keuper. Abril 2013 


\subsection{Parada 2 - CONDICIONAL. TRENCALL D’ESTAVILL (la Pobleta de Bellvei, actualment pertany al terme de la Torre de Cabdella, comarca del Pallars Jussà). (Full 214).}

Des de la parada anterior, cal continuar per la carretera que es dirigeix cap a la Pobleta de Bellvei. Abans d'arribar a aquesta població es troba el trencall d'Estavill, on caldrà parar. En aquest lloc on hi havia una antiga pedrera, on s'explotaven les ofites del Keuper. Així, des de la parada anterior, per tal d'arribar fins aquest indret, s'haurà efectuat un recorregut proper als 4 $\mathrm{Km}$.

En tot aquest recorregut s'han anat trobant els materials triàsics, que s'inclouen entre el Mantell de Zona de les Nogueres, que ja hem trobat a l'aturada anterior. Així, en aquest indret es troba un interessant aflorament de roques ofítiques, incloses entre els materials del Keuper.

Aquestes ofites havien estat explotades en una antiga pedrera. Entre les ofites es trobaven unes mineralitzacions cupríferes amb presència de CALCOPIRITA primària. Per alteració s'ha format ATZURITA i MALAQUITA. També hi ha presència d'HEMATITES. Tot i així, cal dir que unes obres recents, han sepultat la pedrera, ocultant les mineralitzacions; però encara es poden trobar algunes mostres; això si: molt ocasionalment

\subsection{Parada 3. EXPLOTACIONS D'OFITES DE LA CARRETERA DE CASTELL, (el Castell, de l'antic terme municipal de Mont-rós i de l'actual de la Torre de Cabdella, comarca del Pallars Jussà). (Full 214).}

Des de la parada anterior, cal continuar cap a la Pobleta de Bellvei, per tal de fer una fillola, si s'escau. Després, ens caldrà anar cap a la Plana de Mont-rós, per la carretera que es dirigeix cap a Cabdella. Després del penúltim poble, en passar el pont sobre el Noguera de Flamisell, cal agafar el camí que es dirigeix cap al Castell i cap a Antist, sortint per l'esquerra de la ruta principal. Poc abans d'arribar al trencall de Castell, es pot veure una antiga pedrera, situada a I'esquerra de la carretera. Així, des de la parada anterior, haurem recorregut uns $7 \mathrm{Km}$, per tal d’arribar fins aquí.

En aquest recorregut, es penetra plenament dintre del Mantell de la Zona de les Nogueres. En tot aquest tram que s'ha recorregut, $s^{\prime}$ ha anat trobant afloraments paleozoics del Devonià i del Carbonífer. I en arribar al poble abans esmentat, ja es comencen a trobar els nivells rogencs del Permotries. Tanmateix, com en aquest indret, es van trobant afloraments dels materials triàsics del Keuper. Aquí apareixen unes ofites (roques subvolcàniques).

Efectivament, en aquest lloc, hi va haver-hi una antiga explotació d'ofites, destinades a ser emprades com a àrids per a la construcció. (fotografia 3 ). 


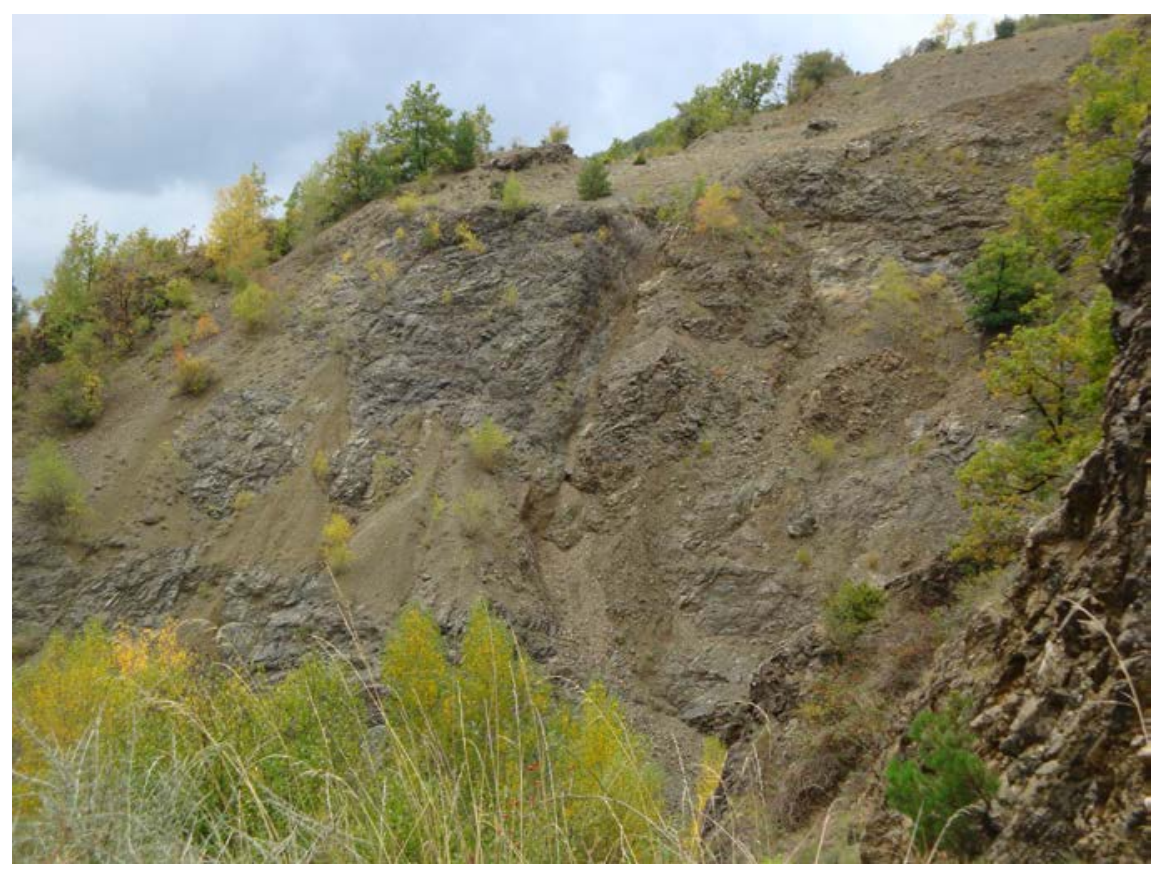

Fotografia 3. Detall de l'explotació d’ofites, de la carretera a Castell. Abril 2013

\subsection{Parada 4. FORNS DE GUIX DEL CASTELL, (el Castell, de l'antic terme municipal de Mont-rós i de l'actual de la Torre de Cabdella, comarca del Pallars Jussà). (Full 214).}

Després d'un recorregut ascendent, de prop de 0 ' $5 \mathrm{Km}$, es troba el trencall que es dirigeix cap al Castell. En arribar al poble, cal continuar uns 50 metres cap al Nord, per tal d'arribar fins a l'indici estudiat). Així, des de la parada anterior, s'haurà efectuat un recorregut de prop de $3 \mathrm{Km}$.

En aquest recorregut, es penetra dintre del Mantell de la Zona de les Nogueres, s'han anat trobant afloraments triàsics i del Permotries.

En aquest indret, a l'entrada del poble (per la part de dalt) es troben uns interessants Forns de Guix, que utilitzaven els guixos del Keuper. Aquests forns formen part del nostre Patrimoni Miner. (fotografía 4). 


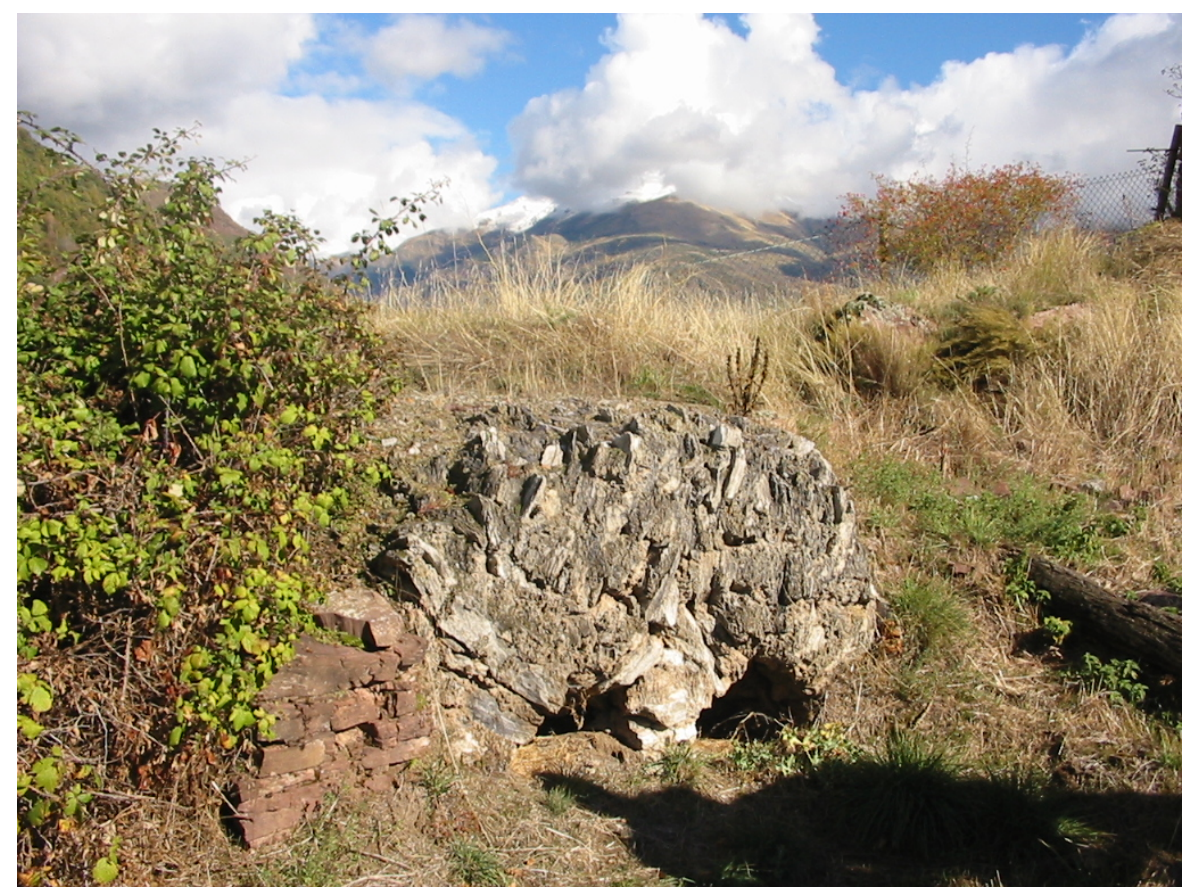

Fotografia4. Forns de Guix del Castell

Curiosament, els dos forns de guix es troben carregats; és a dir en posició de començar a funcionar. Finalment, cal dir que per veure els forns de prop, cal demanar autorització, ja que es troben dintre d'una propietat privada i vallada. Malgrat això, es troben molt prop del camí d'entrada al poble.

\subsection{Parada 5. AFLORAMENTS DE LES MINERALITZACIONS DE LA MINA EUREKA (el Castell, de l'antic terme de Mont-rós i de l'actual de la Torre de Cabdella, comarca del Pallars Jussà). (Full 214).}

Des de la parada anterior, cal continuar cal passar a l'altra banda del poble de Castell, per tal d'anar cap a la part superior de l'antiga Mina Eureka. Així, ara haurem efectuat un recorregut d'uns 0'3 Km, a peu.

En aquest indret hi ha un interessant aflorament de les mineralitzacions cupro-uraniniferes associades a "Red-Bed", que es troben entre els materials rogencs del Permotries, constituïts per nivells detrític. La mineralització té caràcter cupro-uraninífer, amb presència de: CALCOSINA, COVEL.LINA, SIEGENITA, GUMMNITA, URANINITA (el mineral més abundant, entre els d'urani $i$ que es presenta en forma de pechblenda), ATZURITA, MALAQUITA, CARNOTITA, SENGIERITA, TORBERNITA, TYUYANUNUTA y ZEUNEREITA. Amb els anteriors, també hi ha: PIRITA, GOETHITA (limonita), HEMATITES, PIROLUSITA (dendrítica), ANQUERITA, CALCITA, DOLOMITA, SIDERITA i QUARS. També hi ha indicis de: TENORITA i ERITRINA, entre altres minerals.

Un aspecte de la mineralització es pot veure a les fotografies 5 i 6 . 


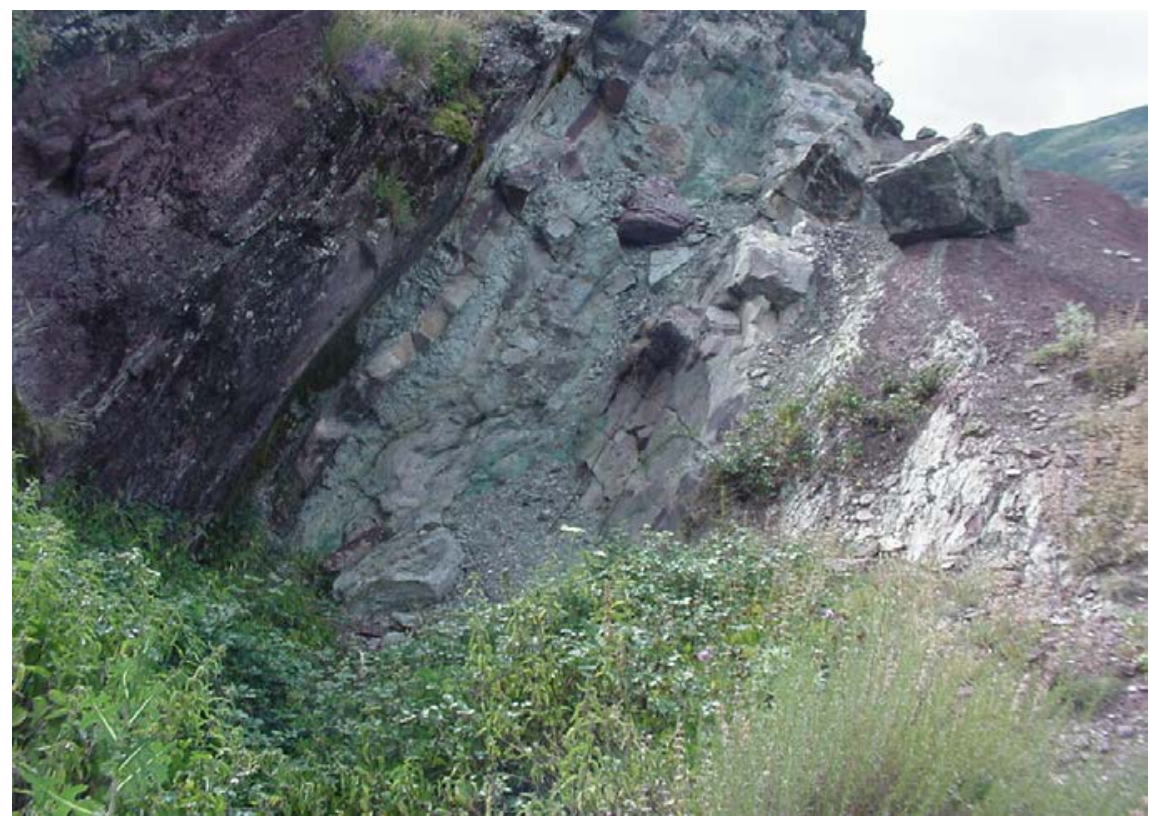

Fotografia 5. Mineralitzacions cupro-uraniníferes a associades a "reb-beds", del Castell. Març 1997

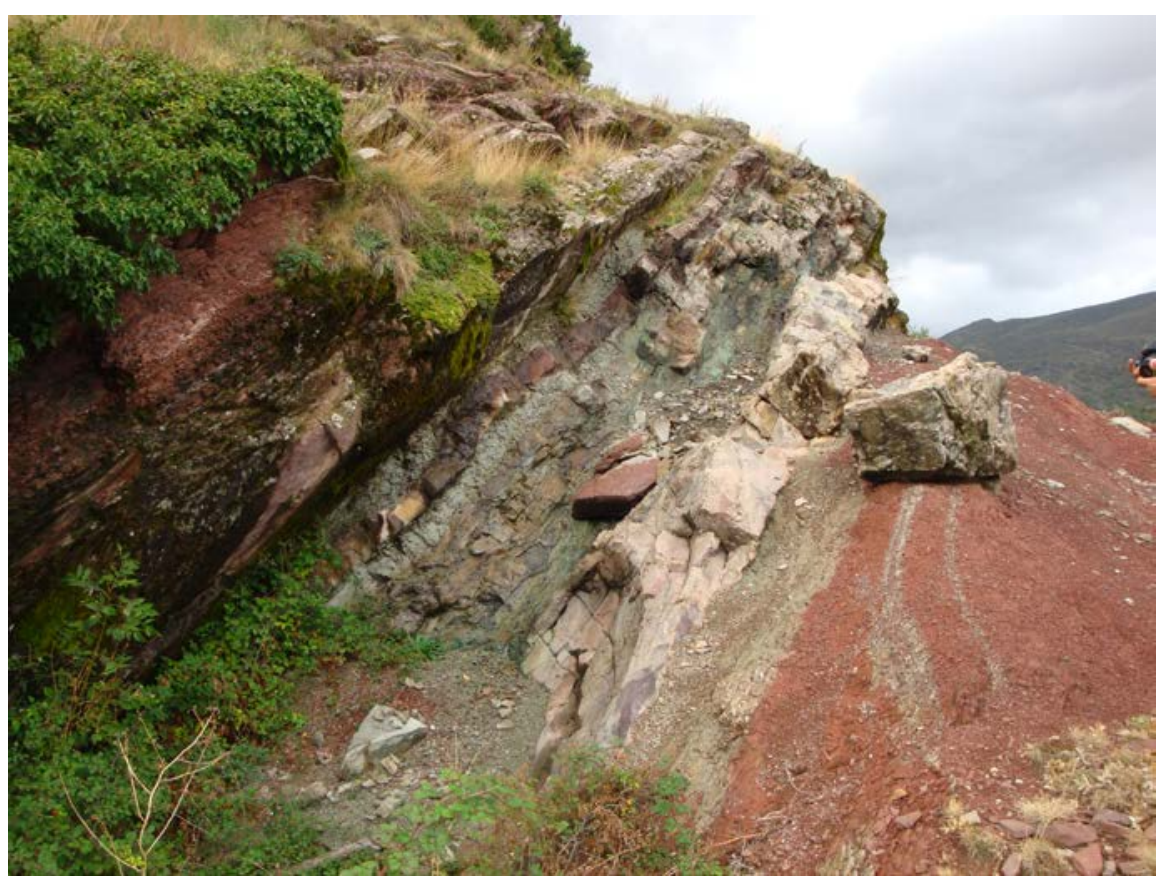

Fotografia 6. Un altre aspecte de les mineralitzacions cupro-uraniníferes a associades a "reb-beds", del Castell, situades entre els materials del Permotries. Març 1997 


\subsection{Parada 6. EXPLOTACIONS MINERES DE LA MINA EUREKA (el Castell, de l'antic terme de Mont-rós i de l'actual de la Torre de Cabdella, comarca del Pallars Jussà). (Full 214).}

Després de fer l'aturada anterior, es pot baixar a peu, per tal d'arribar quasi fins a la carretera. També, es pot baixar fins a l'esmentada carretera i pujar pel corriol que condueix cap el poble del Castell. En qualsevol cas, anirem trobant antigues explotacions mineres al llarg del corriol, des de la parada anterior, fins arribar al descarregador. En aquest recorregut tardarem uns 20 minuts de baixada i uns 35 minuts de pujada. Al llarg de tot aquest recorregut, s'aniran trobant les antigues instal-lacions mineres.

Cal dir que en aquests recorreguts (ascendent o descendent), realitzat pel corriol, haurem trobat sempre afloraments dels materials detrítics del Permotries. Fonamentalment són de tonalitats rogenques, tot i que les mineralitzacions es situen a les zones de tonalitats grisenques. Efectivament, com hem vist a l'aturada anterior, es tracta d'unes importants mineralitzacions cupro-uraniníferes associades a "Red-Bed", que es troben entre els materials rogencs del Permotries, constituïts per nivells detrític.

Així, les mineralitzacions que hem vist a l'aflorament anterior (PARADA 5), han estat explotades en diversos indrets, dintre de la denominada Mina Eureka, situada més avall, entre el poble $\mathrm{i}$ el riu. En aquest trajecte, es troben diverses instal-lacions mineres, tot $\mathbf{i}$ això recomanem no entrar a l'interior de les mines, ja que es troben en un estat molt precari, en moltes de les galeries. (fotografies 7 i 8).

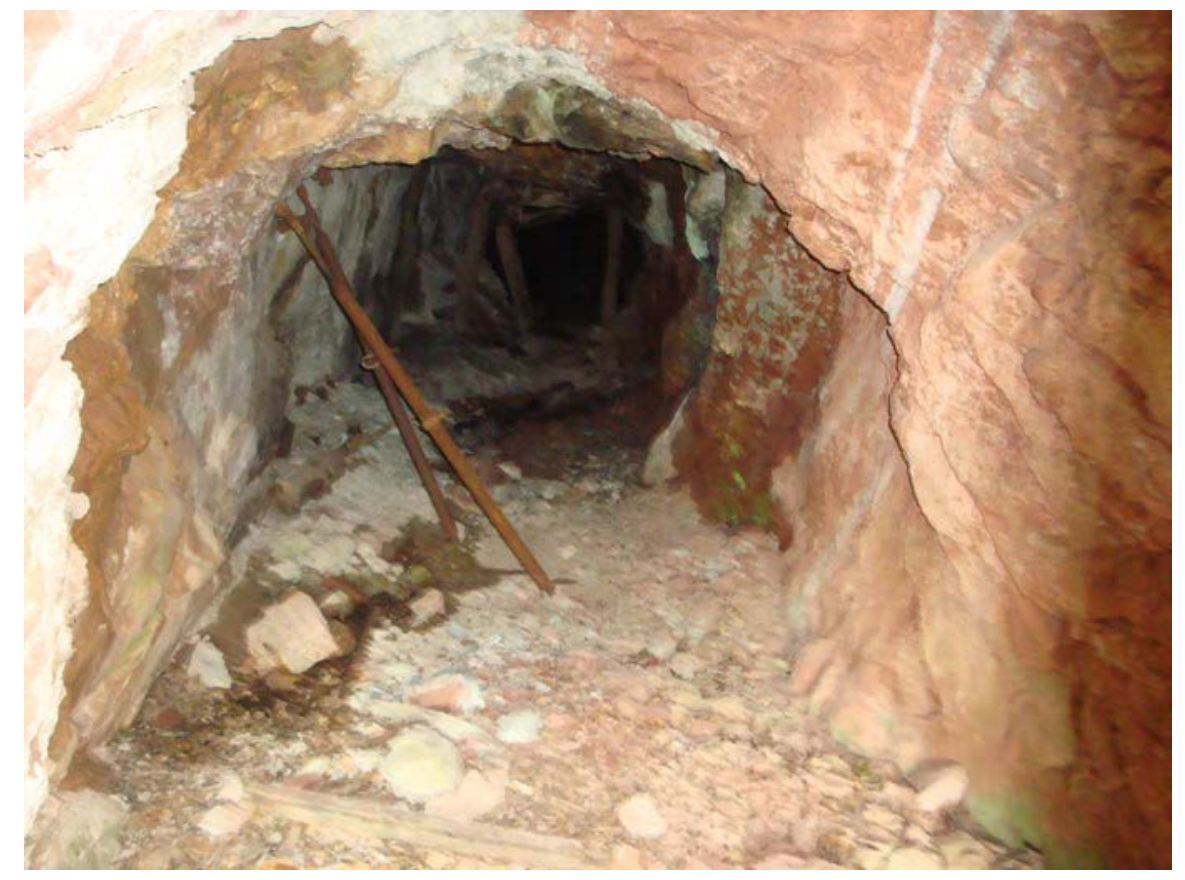

Fotografia 7. Un altre aspecte de l'interior d'una de les galeries de la zona mitja. Abril 2013 


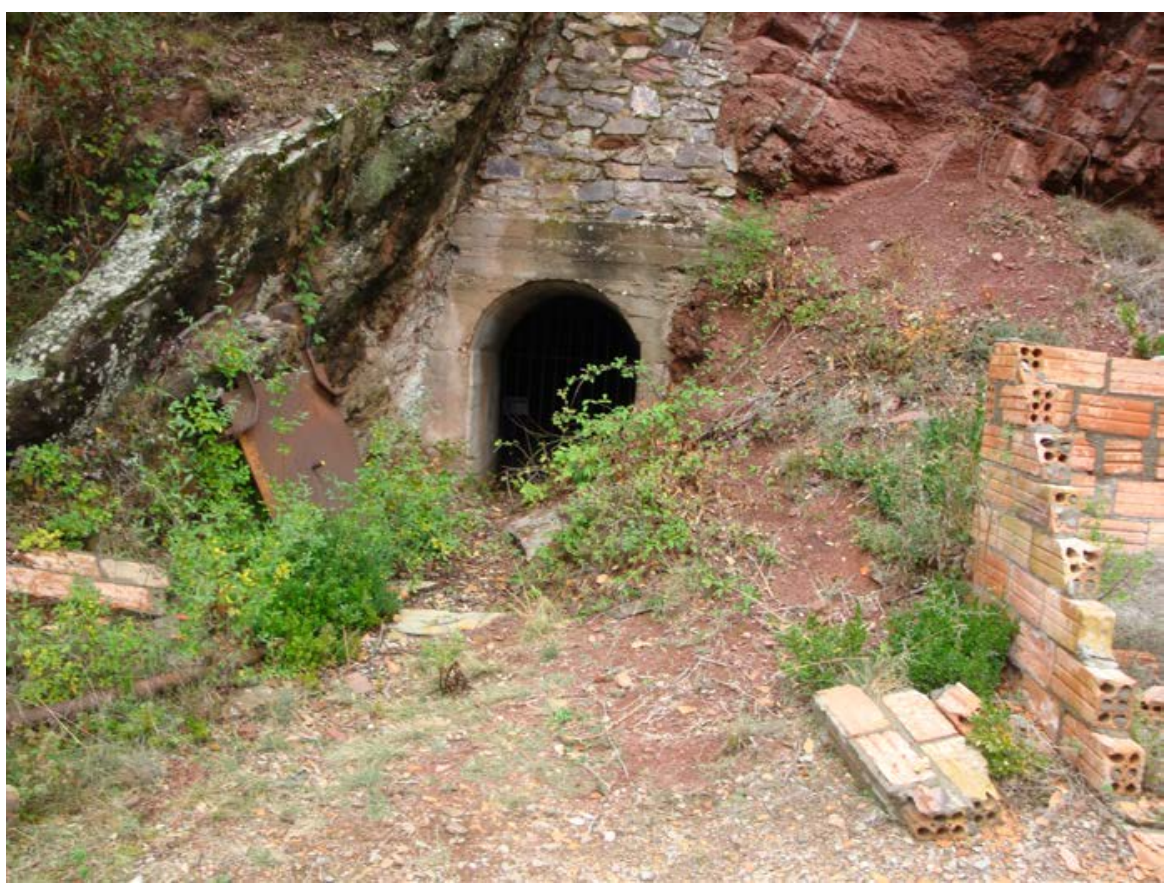

Fotografia 8. Una de les bocamines de la zona Inter mitja de l’explotació

Per altra banda, a la part baixa de les mines, encara es poden veure es instal-lacions de càrrega dels materials estrets. (fotografia 9)

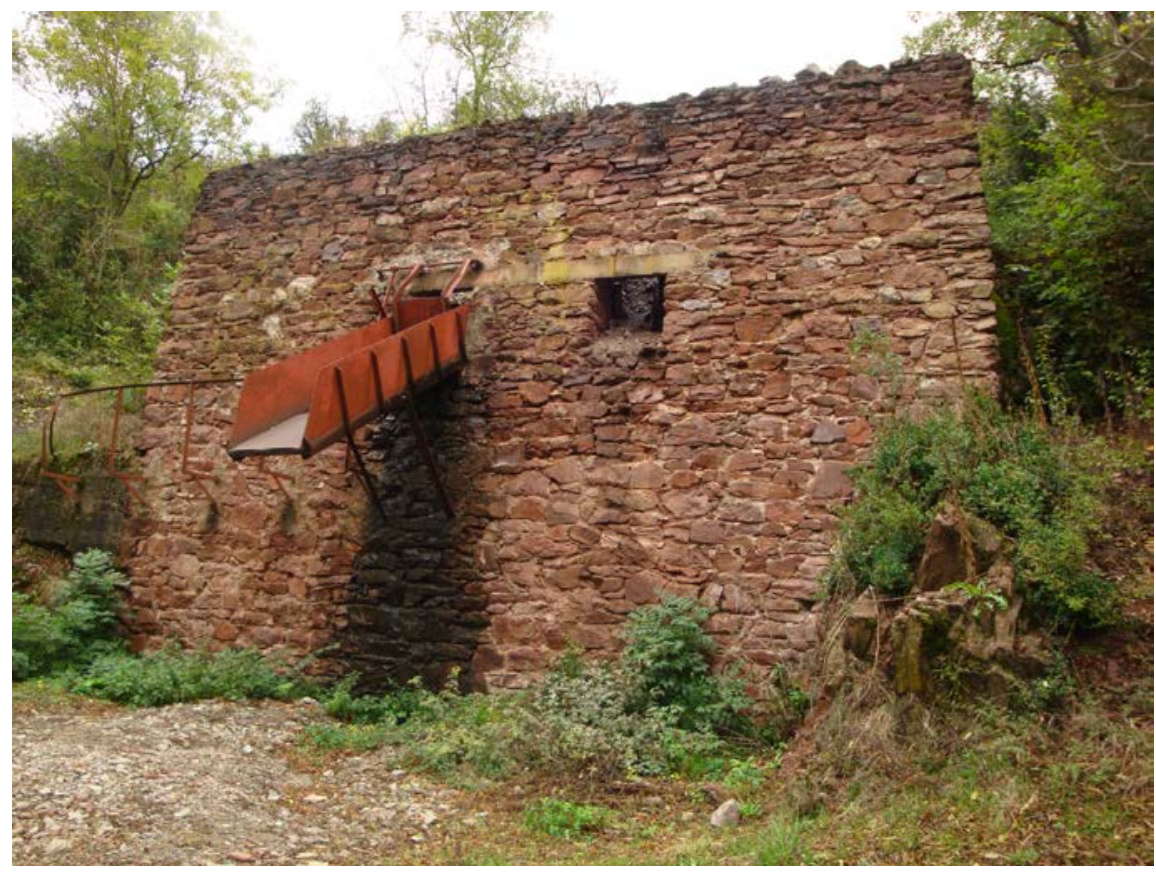

Fotografia 9. Carregador de la Mina Eureka 


\subsection{Parada 7. MINA D’ESPAGUES (Mont-rós, antic terme d'aquest poble, i ara del de Torre de Cabdella, comarca del Pallars Jussà). (Full 214).}

Des de la parada anterior, cal retornar a la carretera, per tal de continuar cap al Nord, arribant així al poblat hidroelèctric de Molinos. Després s'arriba a la cruilla de la carretera que va cap a Mont-rós, i cap a Pobellà. Caldrà agafar-la, i seguir per aquesta darrera ruta, per tal d'anar cap al primer dels dos pobles esmentats.

En arribar-hi, cal agafar la pista que es dirigeix cap al Barranc de Pallerols. I, finalment, cal fer quasi uns $2 \mathrm{Km}$ a peu, per tal d'anar cap a les Bordes de Pallerols, on hi ha les "Mines d'Espagues". Així, des de la parada anterior, s'haurà efectuat un recorregut proper als 5'5 Km.

En aquest recorregut., es van tallant els materials paleozoics del Permià, Carbonífer i Devonià, que es situen al Mantell de la Zona de les Nogueres. Així, a l'indret on hem de fer la present aturada. hi afloren els nivells carbonatats del Devonià.

Pel que fa a la mineralització, cal dir que es tracta d'una formació filoniana, encaixada entre els nivells calcaris del Devonià. Entre els minerals presents, cal fer esment dels següents: ESFALERITA, GALENA, PIRITA, CALCITA i QUARS. També es troben altres minerals; així hi ha: GOETHITA (normalment limonítica i terrosa), CERUSSITA, HIDROCINCITA i SMITHSONITA, entre altres minerals.

\subsection{Parada 8. MINA DE COURE DEL BARRANC DE CUBILLERS, (terme de la Torre de Cabdella, comarca del Pallars Jussà). (Full 214).}

Des de la parada anterior, cal retornar a la carretera principal de la Vall del Flamisell. En arribar-hi, caldrà continuar cap al Nord, per tal d'arribar fins al proper poble de la Torre de Cabdella. Poc després d'arribar-hi, caldrà seguir per un camí que ascendeix per la dreta, just després d'entrar al poble. Aquest camí surt del costat de l'antiga caserna. Seguint-lo, aviat s'arribarà a una antiga zona minera, on efectuarem la present aturada, després de recórrer uns $13 \mathrm{Km}$ des de la parada anterior. (fotografía 10)

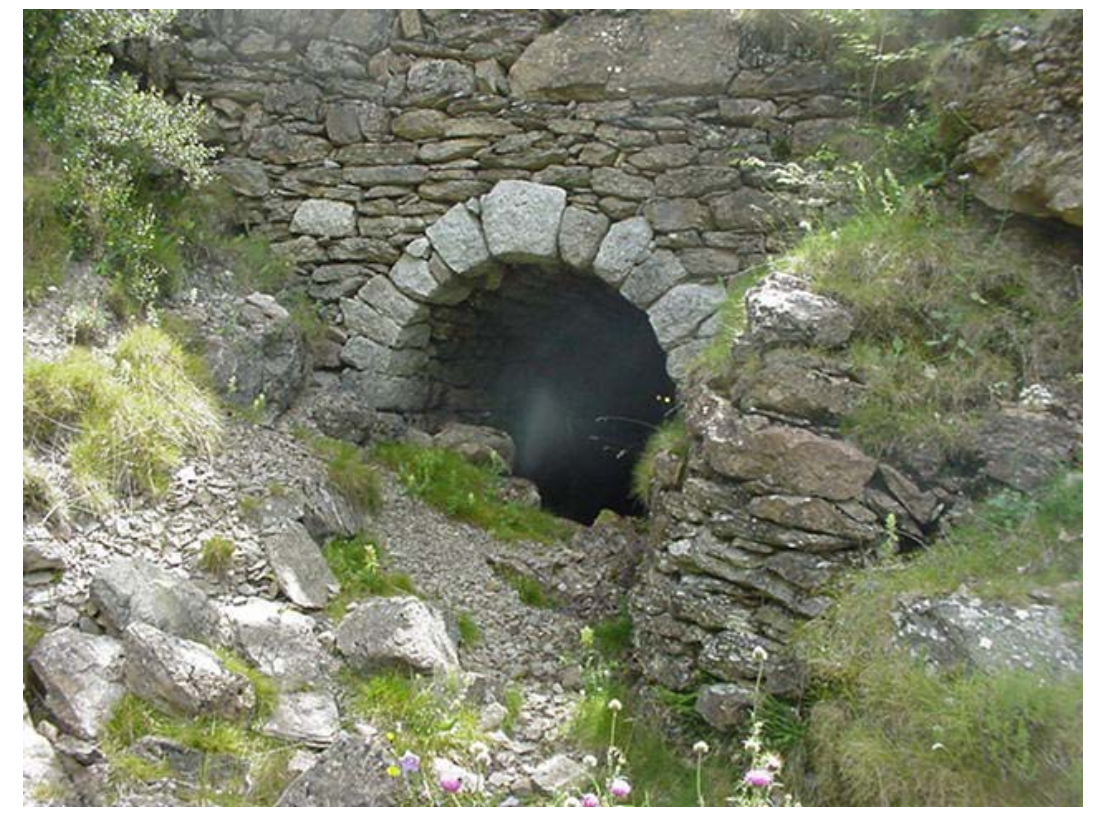

Fotografia 10. Detall d’una de les bocamines de les Mines de coure del Barranc de Cubillers. Abril 2013 
En tot aquest recorregut, s'han anat trobant afloraments dels materials paleozoics, i fonamentalment del Devonià i del carbonífer. Aquests són també els materials que es troben a l'indret de la parada

Aquí es fa clarament palesa una mineralització filoniana, encaixada entre els materials del Devonià. La mineralització té fonamentalment caràcter silícic i cuprífer, amb presència majoritària de QUARS i de CALCOPIRITA. Com a minerals d'alteració es troben entre altres: GOETHITA (limonítica). HEMATITES, ATZURITA i MALAQUITA. També hi ha abundant CALCITA i PIROLUSITA (dendrítica).

Pel que fa a les explotacions mineres, cal dir que van gaudir d'una certa importància durant els finals del passat segle XIX (així com part del XX). Tot i així, aquestes explotacions es troben en estat ruïnós, essent perilloses a l'hora d'entrar-hi. (fotografía 11).

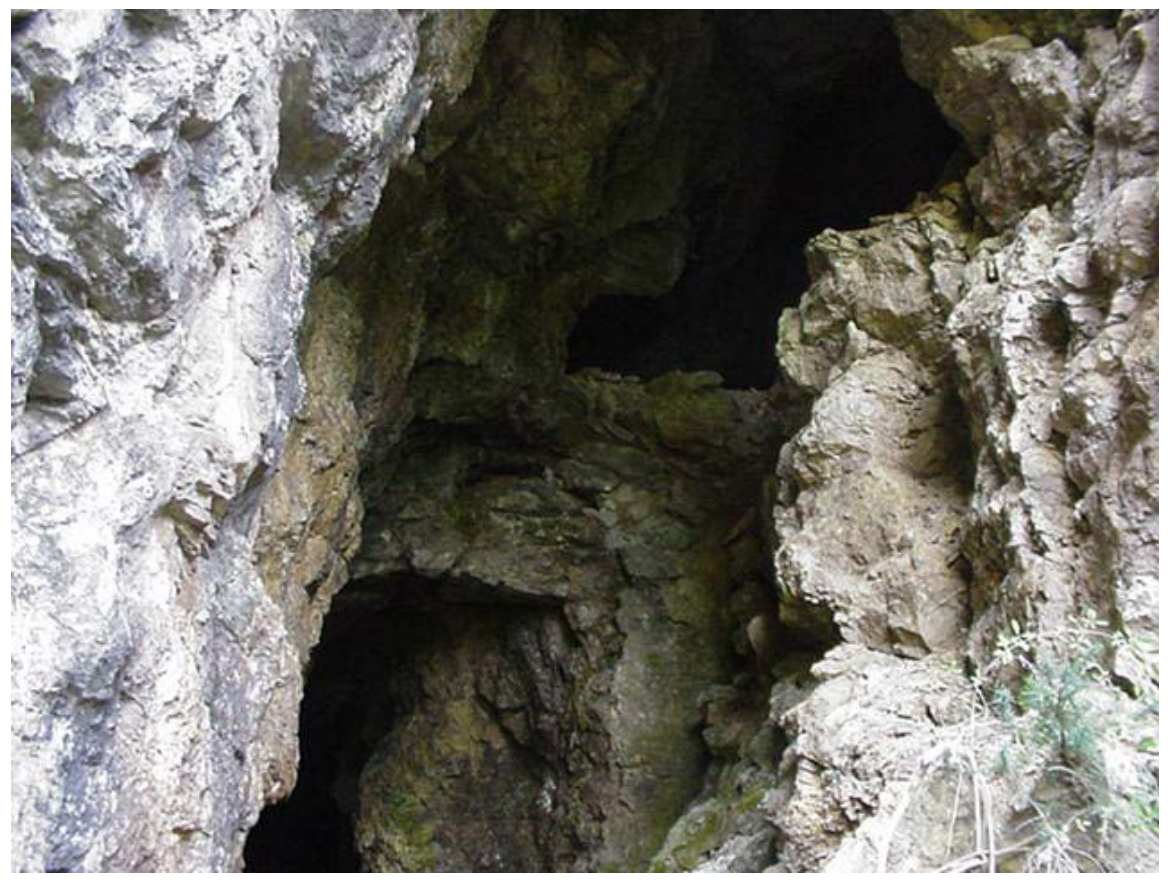

Fotografía 11.Una de les altres bocamines

En aquest indret finalitza el recorregut de l'itinerari 


\section{Bibliografia}

GUIMERÀ, J. et altri (1992).- Geologia (II), Història Natural dels Països Catalans, Vol. 2, 547 pag. Enciclopèdia Catalana, S.A. Barcelona.

IGME (1994).- Mapa Geológico de España a escala 1:50.000 (Plan Magna). Fulla i Memòria nº 252 (Tremp). Inst. GeoMinero y Tecnol. España. Minist. Indústria. Madrid.

MATA-PERELLÓ, J.M. (1991).- Els Minerals de Catalunya. Arxius de la Secció de Ciències de I'Institut d'Estudis Catalans, vol.47, 545 pàgines. Barcelona.

MATA-PERELLÓ, J.M. (1995).- Itinerari Geològico-Mineralògic pel Pallars Jussà i pel Pallars Sobirà: des de Puimanyons a Sort. Inèdit, 13 pàgines. Barcelona.

MATA-PERELLÓ, J.M. (1996a).- Selecció d'itineraris geològics i mineralògics per les terres de Lleida. Pub. Museu de Geologia "Valentí Masachs", 72 pàgines. Manresa.

MATA-PERELLÓ, J.M. (1996b).- Itinerari Geològico-Mineralògic per la comarca de la Noguera: des de Bellmunt d'Urgell a Camarasa i al Pas de Terradets, Inèdit, 16 pàgines. Manresa.

MATA-PERELLÓ, J.M. (1998a).- Recorregut de recerca geològica I mineralògica per les comarques de la Noguera I del Pallars Jussà: des de Balaguer a Tartareu, I des d'Ager a Puigcercós. Algeps, sèrie $B, \mathrm{n}^{\circ} 89,16$ pàgines. Manresa.

MATA-PERELLÓ, J.M. (1998b).- Recerca geològica I mineralògica per les comarques de la Noguera I del Pallars Jussà: des del Pont d'Alentorn a Vilanova de Meià, I des del Pas Nou al Congost d’Erinyà. Algeps, sèrie $B, n^{\circ}$ 97, 14 pàgines. Manresa.

MATA-PERELLÓ, J. M. (2000).- Recorregut de recerca geològica i mineralògica per les comarques de l'Alta Ribagorça i de la Val d'Aran: des de Malpàs al Túnel de Vielha, per Pont de Suert. Terra Endins, $\mathrm{n}^{\circ} 18,10$ pàg. Manresa.

MATA-PERELLÓ, J.M. (2002a).- Recorregut de recerca geològica i mineralògica per les comarques del Pallars Jussà i de l'Alta Ribagorça: des de la Pobla de Segur a Xerallo i al Pont de Suert. Inèdit. 12 pag. Manresa.

MATA-PERELLÓ, J.M. (2002b).- Recorregut de recerca geològica i mineralògica per les comarques del Pallars Jussà i de I'Alta Ribagorça: des de Senterada a Xerallo, la Vall de Manyanet i al Pont de Suert. Inèdit. 12 pag. Manresa.

MATA-PERELLÓ, J.M. (2003).- Recorregut de recerca geològica i mineralògica per les comarques del Pallars Jussà i de l'Alta Ribagorça: des de la Pobla de Segur a Xerallo, Adons i al Viu de Llevata. Inèdit, 8 pag. Manresa.

MATA-PERELLÓ, J.M. (2009).- Recorregut de recerca geològica i mineralògica per les comarques del Pallars Jussà i de l'Alta Ribagorça: des de Senterada a Xerallo i al Pont de Suert. Inèdit. 10 pàgines. Manresa.

MATA-PERELLÓ, J.M. (2009b).- Recorregut de recerca Geològica i Mineralògica per les terres dels dos Pallars: des de Senterada cap a la Torre de Cabdella i a Gerri de la Sal. Inèdit. 10 pàgines. Manresa.

MATA-PERELLÓ, J.M. (2010).- Recorregut de recerca geològica i mineralògica per les comarques del Pallars Jussà i de l'Alta Ribagorça: des de la Pobla de Segur a Senterada, Xerallo i al Pont de Suert. Inèdit. 10 pàgines. Manresa. 
MATA-PERELLÓ, J.M. (2012).- Recorregut de recerca geològica i mineralògica per la comarca del Pallars Jussà: des de la Pobla de Segur a Senterada, a la Pobleta de Bellveí i a Cabdella. Inèdit. 12 pàgines. Manresa.

MATA-PERELLÓ, J.M. (2013).- Recorregut de recerca geològica i mineralògica per la comarca del Pallars Jussà: des de Senterada, a la Pobleta de Bellveí, a la Plana de Mont-ros, a Cabdella i a Sallente. Inèdit. 14 pàgines. Manresa.

MATA-PERELLÓ, J.M. i MATA LLEONART, R. (2000a).- Recorregut de recerca geològica i mineralògica per les comarques de la Noguera i del Pallars Jussà: des del Pas de Terradets a Puigcercós i al Congost d'Erinyà, Terra Endins, nº 15, 10 pàg. Manresa.

MATA-PERELLÓ, J.M. i MATA LLEONART, R. (2000b).- Recorregut de recerca geològica i mineralògica per les comarques del Pallars Jussà i de I'Alta Ribagorça: des de Senterada al Pont de Malpàs, Terra Endins, nº 17, 7 pàg. Manresa.

MATA-PERELLÓ, J. M. i MONTANÉ i GARCÍA, P. (2002).- Recorregut de recerca de geològica i mineralògica per les comarques de I'Alta Ribagorça i del Pallars Jussà: des de la Pressa de Colomers a Malpàs i a la Vall de Manyanet. Inèdit, 12 pag. Manresa.

MATA-PERELLÓ, J.M. i SANZ BALAGUÉ, J. (1993).- Guía de identificación de Minerales, adaptada fundamentalmente a la Península Ibérica. Parcir, Edic. Selectas, 243 pàgines. Manresa.

RIBA ARDERIU, O. et altri (1976).- Geografia Física dels Països Catalans. Edit Ketres. 211 pàgines. Barcelona.

ROSELL SANUI, J. (1970).- Explicació del Mapa Geològic, a escala 1:50.000, corresponent al full no 252 (Tremp). Mapa Geológico de España. Inst. Geológico y Minero de España. Madrid. 